\title{
Clinical utility gene card for: Aniridia
}

\author{
Rose Richardson $^{1}$, Melanie Hingorani ${ }^{2}$, Veronica Van Heyningen ${ }^{1}$, Cheryl Gregory-Evans ${ }^{3}$ \\ and Mariya Moosajee ${ }^{\star, 1,2,4}$
}

European Journal of Human Genetics (2016) 24, doi:10.1038/ejhg.2016.73; published online 6 July 2016

\section{DISEASE CHARACTERISTICS}

1.1 Name of the disease (synonyms)

Aniridia (Aniridia II).

\subsection{OMIM\# of the disease}

106210.

1.3 Name of the analysed genes or DNA/chromosome segments: PAX6, ELP4

\subsection{OMIM\# of the gene(s)}

607108 (PAX6), 606985 (ELP4).

\subsection{Mutational spectrum}

Approximately two-thirds of aniridia cases are familial with autosomal dominant inheritance, the remainder are sporadic. ${ }^{1}$ Aniridia occurs either as an isolated ocular abnormality or as part of the Wilms tumour-aniridia-genital anomalies-retardation (WAGR) syndrome (see Clinical Utility Gene Card for WAGR syndrome ${ }^{2}$ ). Loss of function of one copy of the PAX6 gene (NCBI reference sequence NM_001310160.1 and NM_001310161.1) occurs in around $90 \%$ of aniridia cases, with intragenic variants accounting for two-thirds and chromosomal rearrangements for one-third of patients. Over $94 \%$ of all intragenic point variants result in either premature termination codons (mainly through nonsense, splice and frame-shift insertions or deletions), C-terminal extensions (CTE) or missense changes. ${ }^{1}$ To date (January 2016), 403 unique PAX6 gene variants have been submitted to the online Human PAX6 Mutation Database (http:// pax6/hgu.mrc.ac.uk/). These variants are scattered throughout the PAX6 gene, generally disrupting transcription or translation. To date, of the 696 public entries in the PAX6 Mutation Database, over 100 different premature termination codons are recorded, with $\sim 20 \%$ accounted for by just four common nonsense variants of arginine (R) residues: c.607C $>$ T, p.R203* $(36$ reports); c.718C $>$ T, p.R240* (48 reports); c.781C > T, p.R261* (19 reports); and c. $949 \mathrm{C}>\mathrm{T}, \mathrm{p} . \mathrm{R} 317^{\star}$ (35 reports). The CTE variants are associated with more severe aniridic phenotypes, ${ }^{3,4}$ the $c .1267 d u p T$ has been reported 21 times.

One case of aniridia was reported to have been caused by a heterozygous point variant in the ultra-conserved PAX6 cis-regulatory element (SIMO) that resides $150 \mathrm{~kb}$ downstream from PAX6 in intron 9 of the ELP4 gene (NCBI reference sequence NM_001288726.1). ${ }^{5}$ Deletion of regulatory elements, or their separation from the PAX6 transcription machinery through inversion or translocation breakpoints, may manifest with a classical aniridic phenotype. There have been a few reports on aniridia-like phenotypes secondary to variants in FOXC1. ${ }^{6,7}$

\subsection{Analytical methods}

Array comparative genomic hybridisation or multiplex ligationdependent probe amplification assay (MLPA) should be performed initially to detect deletions or duplications, then bi-directional fluorescent Sanger sequencing of coding and intron-exon boundaries of PAX6 should follow. Some molecular service labs offer fluorescence in situ hybridisation to identify rearrangements that may disrupt PAX6 without copy number change. ${ }^{8,9}$

\subsection{Analytical validation}

Parallel bi-directional fluorescent Sanger sequencing of known controls is required to validate procedures. Diagnostic testing must be carried out within a laboratory environment working to standards compliant with the ISO 15189.

1.8 Estimated frequency of the disease (Incidence at birth ('birth prevalence') or population prevalence)

If known to be variable between ethnic groups, please report):

The prevalence of aniridia in the general population is between 1 in 40 000-100 000 with no known predilection for a particular race or gender.

\subsection{Diagnostic setting:}

\begin{tabular}{lll}
\hline & Yes & No \\
A. (Differential) diagnostics & $\bigotimes$ & $\square$ \\
B. Predictive testing & $\bigotimes$ & $\square$ \\
C. Risk assessment in relatives & $\bigotimes$ & $\square$ \\
D. Prenatal & $\bigotimes$ & $\square$
\end{tabular}

Comment: Not applicable.

\footnotetext{
${ }^{1}$ Department of Ocular Biology and Therapeutics, UCL Institute of Ophthalmology, London, UK; ${ }^{2}$ Department of Genetics, Moorfields Eye Hospital NHS Foundation Trust, London, UK; ${ }^{3}$ Department of Ophthalmology and Visual Sciences, University of British Columbia, Vancouver, British Columbia, Canada; ${ }^{4}$ Department of Ophthalmology, Great Ormond Street Hospital, London, UK

${ }^{*}$ Correspondence: Dr M Moosajee, Department of Ocular Biology and Therapeutics, UCL Institute of Ophthalmology, 11-43 Bath Street, London EC1V 9EL, UK. Tel: +44 207 608 6971; Fax: +44 207608 6830; E-mail: m.moosajee@ucl.ac.uk

Received 18 January 2016; revised 28 April 2016; accepted 26 May 2016; published online 6 July 2016
} 


\section{TEST CHARACTERISTICS}

\begin{tabular}{|c|c|c|c|c|}
\hline & \multicolumn{2}{|c|}{ Genotype or disease } & \multirow{2}{*}{$\begin{array}{l}\text { A: True positives } \\
\text { B: False positives }\end{array}$} & \multirow{2}{*}{$\begin{array}{l}\text { C: False negative } \\
\text { D: True negative }\end{array}$} \\
\hline & Present & Absent & & \\
\hline \multicolumn{5}{|l|}{ Test } \\
\hline Positive & A & B & $\begin{array}{l}\text { Sensitivity: } \\
\text { Specificity: }\end{array}$ & $\begin{array}{l}A /(A+C) \\
D /(D+B)\end{array}$ \\
\hline Negative & C & $\mathrm{D}$ & $\begin{array}{l}\text { Positive predictive value: } \\
\text { Negative predictive value: }\end{array}$ & $\begin{array}{l}A /(A+B) \\
D /(C+D)\end{array}$ \\
\hline
\end{tabular}

\subsection{Analytical sensitivity}

(proportion of positive tests if the genotype is present)

The analytical sensitivity and specificity of bi-directional Sanger sequencing is estimated to be $>98 \%$ for the detection of nucleotide base changes, small deletions and insertions in the regions analysed. Analytical sensitivity and specificity of MLPA testing is essentially $100 \%$ with appropriate testing; very rarely sub-microscopic deletions may reduce analytical sensitivity of MLPA. Patients who appear not to have variants on testing described above, may have deep intronic or other variants in the regulatory elements missed through exonic analysis.

\subsection{Analytical specificity \\ (proportion of negative tests if the genotype is not present)}

See above. Estimated analytical specificity of $>98 \%$ given current testing methodologies, based on false positives that may arise due to misinterpretation of rare polymorphic variants that rarely occur in Sanger sequencing.

\subsection{Clinical sensitivity}

(proportion of positive tests if the disease is present)

The clinical sensitivity can be dependent on variable factors such as age or family history. In such cases a general statement should be given, even if a quantification can only be made case by case.

Aniridia presents in infancy, typically characterised by complete or partial iris hypoplasia and foveal hypoplasia, resulting in reduced visual acuity and nystagmus. There are progressive features including cataract, glaucoma and corneal abnormalities. The clinical sensitivity is $>98 \%$. Although rare phenocopies do exist and include dominant alleles of FOXC1, PITX2 and PITX3 which can cause diagnostic difficulties. ${ }^{6,7,10,11}$ Phenotypically subtle PAX6 variants have been documented, ${ }^{12-14}$ including those that segregate with nystagmus, foveal hypoplasia and autosomal dominant keratitis in the absence of iris abnormalities supporting the concept of gene dosage effects, variable expressivity and gonadal mosaicism. ${ }^{15}$ Deep phenotyping studies have revealed smaller corpus callosum area on brain volumetry following magnetic resonance imaging, and subtle hearing difficulties associated with interhemispheric transfer problems. ${ }^{16}$ The clinical examination alone in atypical phenotypes would not lead to a PAX6related molecular diagnosis, highlighting the importance of genetic testing.

\subsection{Clinical specificity}

\section{(proportion of negative tests if the disease is not present)}

The clinical specificity can be dependent on variable factors such as age or family history. In such cases a general statement should be given, even if a quantification can only be made case by case.
Aniridia is a congenital disorder, a positive test in a patient without signs of this condition is unlikely, and hence the clinical specificity will be high, nearing $100 \%$.

2.5 Positive clinical predictive value (life-time risk of developing the disease if the test is positive)

Estimated $>99 \%$ for PAX6 variants, as aniridia presents in infancy with high penetrance.

2.6 Negative clinical predictive value (probability of not developing the disease if the test is negative)

Assume an increased risk based on family history for a non-affected person. Allelic and locus heterogeneity may need to be considered.

Index case in that family had been tested:

Nearly $100 \%$ if no aniridia.

Index case in that family had not been tested:

Nearly $100 \%$ if no aniridia, however the clinical phenotype can be variable with subtle signs and familial recurrence if parental mosaicism, partial or non-penetrance exists, therefore it is recommended that the family is tested. ${ }^{17}$

\section{CLINICAL UTILITY}

3.1 (Differential) diagnostics: The tested person is clinically affected (To be answered if in 1.9 'A' was marked)

\subsubsection{Can a diagnosis be made other than through a genetic test?}

\begin{tabular}{lll}
\hline No (continue with 3.1.4) & $\square$ & \\
Yes & $\square$ & $\square$ \\
& Clinically & $\square$ \\
& Imaging & $\square$ \\
& Endoscopy & $\square$ \\
& Biochemistry & $\square$ \\
& Electrophysiology & \\
& Other (please describe) & \\
\end{tabular}

3.1.2 Describe the burden of alternative diagnostic methods to the patient

Patients with suspected aniridia can be diagnosed based on clinical examination, predominantly with the slit-lamp (hand-held for infants) to identify iris and pupillary abnormalities, corneal opacification and vascularisation, and cataract or glaucoma. Fundoscopy (indirect ophthalmoscopy for infants) may reveal foveal hypoplasia and associated optic nerve abnormalities, however, an examination under anaesthesia may be required. Optical coherence tomography (OCT) may be useful to document foveal hypoplasia, but this may be difficult in the presence of nystagmus and in young children, though hand-held OCT may help. ${ }^{18}$ If severe corneal opacity or oedema exists due to congenital glaucoma, anterior segment ultrasound biomicroscopy may aid detection of any iris defects.

3.1.3 How is the cost effectiveness of alternative diagnostic methods to be judged?

Aniridia is a rare disorder, and patients will often require tertiary referral for accurate diagnosis. Clinical examination provides a cost-effective diagnosis, but high-resolution imaging can be costly. 
3.1.4 Will disease management be influenced by the result of a genetic test?

\begin{tabular}{|c|c|c|}
\hline \multirow{5}{*}{$\begin{array}{l}\text { No } \\
\text { Yes }\end{array}$} & $\square$ & \\
\hline & $\otimes$ & \\
\hline & $\begin{array}{l}\text { Therapy } \\
\text { (please describe) }\end{array}$ & $\begin{array}{l}\text { Pharmacological approaches such as translational bypass } \\
\text { therapy using ataluren are being developed to treat } \\
\text { nonsense-mediated aniridia. }{ }^{19}\end{array}$ \\
\hline & $\begin{array}{l}\text { Prognosis } \\
\text { (please describe) }\end{array}$ & $\begin{array}{l}\text { The genotype has been associated with disease severity; null } \\
\text { variants predominantly cause classical aniridia with iris } \\
\text { aplasia and progressive sight-threatening disease. }{ }^{3} \text { CTE } \\
\text { variants are associated with more severe aniridic } \\
\text { phenotypes, }{ }^{4} \text { whereas missense variants produce a variable } \\
\text { spectrum ranging from mild iris defects and preserved visual } \\
\text { acuity to severe features including optic nerve malforma- } \\
\text { tions, Peters anomaly and microphthalmia. }{ }^{20,21}\end{array}$ \\
\hline & $\begin{array}{l}\text { Management } \\
\text { (please describe) }\end{array}$ & $\begin{array}{l}\text { Aniridia should be managed by specialists with expertise in } \\
\text { this condition. Supportive measures for those with sight } \\
\text { impairment include involvement of social services. Regular } \\
\text { follow-up will be required to monitor progression of corneal } \\
\text { disease, cataract and glaucoma with medical and surgical } \\
\text { interventions where needed. Regular refraction and provi- } \\
\text { sion of tinted or photochromic lenses to reduce light } \\
\text { sensitivity. Genetic counselling will be offered to the family. } \\
\text { Audiological evaluation may help identify and support early } \\
\text { school age children with aniridia-associated central auditory } \\
\text { processing deficits. }{ }^{15}\end{array}$ \\
\hline
\end{tabular}

3.2 Predictive Setting: The tested person is clinically unaffected but carries an increased risk based on family history

(To be answered if in 1.9 'B' was marked)

\subsubsection{Will the result of a genetic test influence lifestyle and} prevention?

If the test result is positive The result may impact on career choices and inform (please describe) family planning. Currently, no medical or lifestyle therapies exist to prevent sight deterioration or disease progression. If a deletion involves both PAX6 and WT1 leading to a risk of Wilms tumour, the influence on lifestyle will significantly change, please refer to the management section of the Clinical Utility Gene Card for WAGR syndrome. ${ }^{2}$

If the test result is negative The result will inform family planning. (please describe)

3.2.2 Which options in view of lifestyle and prevention does a person at-risk have if no genetic test has been done (please describe)?

Some aniridic patients may be 'legally blind' or experience progressive vision loss making professions that require perfect vision near impossible. Hence, a clinically confirmed diagnosis can help to provide guidance in career choice.

3.3 Genetic risk assessment in family members of a diseased person (To be answered if in 1.9 ' $\mathrm{C}$ ' was marked)

3.3.1 Does the result of a genetic test resolve the genetic situation in that family?

Yes.
3.3.2 Can a genetic test in the index patient save genetic or other tests in family members?

No. Parents of an index patient with a de novo gene variant should be examined for subtle aniridic changes, and be checked for parental mosaicism or non-penetrance.

3.3.3 Does a positive genetic test result in the index patient enable a predictive test in a family member?

Yes. Seventy percent of patients with isolated aniridia have an affected parent. ${ }^{22}$ Risk to siblings is dependent on the genetic status of the proband's parents. ${ }^{23}$

\subsection{Prenatal diagnosis}

(To be answered if in 1.9 ' $\mathrm{D}$ ' was marked)

Prenatal diagnosis is offered to patients with a confirmed diseasecausing PAX6 variant or regulatory region deletion to enable them to be fully informed, however, acting upon the result in terms of termination is not normally advised as this condition can have a variable clinical phenotype. An individual with isolated aniridia has a $50 \%$ chance of passing the PAX6 pathogenic variant to their offspring. If the parents appear unaffected but they have an affected child, rare germ line mosaicism can exist, this should be investigated in order to identify the risk to further siblings.

3.4.1 Does a positive genetic test result in the index patient enable a prenatal diagnosis?

Yes. Prenatal testing using foetal cells obtained by amniocentesis $(\sim 15-$ 18 weeks gestation) or chorionic villus sampling $(\sim 10-12$ weeks gestation) is possible for pregnancies at increased risk for isolated aniridia if the pathogenic variant or regulatory region deletion has been identified. ${ }^{24}$

\section{IF APPLICABLE, FURTHER CONSEQUENCES OF TESTING}

Please assume that the result of a genetic test has no immediate medical consequences. Is there any evidence that a genetic test is nevertheless useful for the patient or his/her relatives? (Please describe)

Yes. Understanding the genetic result provides information regarding recurrence risk, inheritance patterns, facilitates decision making through effective genetic counselling, enables patients to participate in research studies including clinical trials and join organisations such as the Aniridia Foundation International (AFI) for support and guidance.

\section{CONFLICT OF INTEREST}

The authors declare no conflict of interest.

\section{ACKNOWLEDGEMENTS}

This work was supported by EuroGentest2 (Unit 2: 'Genetic testing as part of health care'), a Coordination Action under FP7 (Grant Agreement Number 261469) and the European Society of Human Genetics. MM gratefully acknowledges the support of the National Institute for Health Research (NIHR) Biomedical Research Centre based at Moorfields Eye Hospital NHS Foundation Trust and UCL Institute of Ophthalmology.

1 Hingorani M, Hanson I, van Heyningen V: Aniridia. Eur J Hum Genet 2012; 20 1011-1017.

2 Clericuzio C, Hingorani M, Crolla JA, van Heyningen V, Verloes A: Clinical utility gene card for: WAGR syndrome. Eur J Hum Genet 2011; e-pub ahead of print 12 January 2011; doi:10.1038/ejhg.2010.220.

3 Hingorani M, Williamson KA, Moore AT, van Heyningen V: Detailed ophthalmologic evaluation of 43 individuals with PAX6 mutations. Invest Ophthalmol Vis Sci 2009; 50 2581-2590. 
4 Aggarwal S, Jinda W, Limwongse C, Atchaneeyasakul LO, Phadke SR: Run-on mutation in the PAX6 gene and chorioretinal degeneration in autosomal dominant aniridia. Mol Vis 2011; 17: 1305-1309.

5 Bhatia S, Bengani H, Fish M et al: Disruption of autoregulatory feedback by a mutation in a remote, ultraconserved PAX6 enhancer causes aniridia. Am J Hum Genet 2013; 93: $1126-1134$.

6 Khan AO, Aldahmesh MA, Al-Amri A: Heterozygous FOXC1 mutation (M161K) associated with congenital glaucoma and aniridia in an infant and a milder phenotype in her mother. Ophthalmic Genet 2008; 29: 67-71.

7 Ito YA, Footz TK, Berry FB et al: Severe molecular defects of a novel FOXC1 W152G mutation result in aniridia. Invest Ophthalmol Vis Sci 2009; 50: 3573-3579.

8 Crolla JA, van Heyningen V: Frequent chromosome aberrations revealed by molecular cytogenetic studies in patients with aniridia. Am J Hum Genet 2002; 71: 1138-1149.

9 Robinson DO, Howarth RJ, Williamson KA et al: Genetic analysis of chromosome $11 \mathrm{p} 13$ and the PAX6 gene in a series of 125 cases referred with aniridia. Am J Med Genet A 2008; 146A: 558-569.

10 Perveen R, Lloyd IC, Clayton-Smith J et al: Phenotypic variability and asymmetry of Rieger syndrome associated with PITX2 mutations. Invest Ophthalmol Vis Sci 2000; 41: 2456-2460.

11 Semina EV, Ferrell RE, Mintz-Hittner HA et al: A novel homeobox gene PITX3 is mutated in families with autosomal-dominant cataracts and ASMD. Nat Genet 1998; 19: 167-170.

12 Gronskov K, Rosenberg T, Sand A, Brondum-Nielsen K: Mutational analysis of PAX6: 16 novel mutations including 5 missense mutations with a mild aniridia phenotype. Eur J Hum Genet 1999; 7: 274-286.

13 Morrison D, FitzPatrick D, Hanson I et al: National study of microphthalmia, anophthalmia, and coloboma (MAC) in Scotland: investigation of genetic aetiology. J Med Genet 2002; 39: 16-22.
14 Mirzayans F, Pearce WG, MacDonald IM, Walter MA: Mutation of the PAX6 gene in patients with autosomal dominant keratitis. Am J Hum Genet 1995; 57: 539-548.

15 Thomas S, Thomas MG. Andrews C et al: Autosomal-dominant nystagmus, foveal hypoplasia and presenile cataract associated with a novel PAX6 mutation. Eur J Hum Genet 2014; 22: 344-349.

16 Bamiou DE, Free SL, Sisodiya SM et al: Auditory interhemispheric transfer deficits, hearing difficulties, and brain magnetic resonance imaging abnormalities in children with congenital aniridia due to PAX6 mutations. Arch Pediatr Adolesc Med 2007; 161: 463-469.

17 Hanson I, Churchill A, Love J et al: Missense mutations in the most ancient residues of the PAX6 paired domain underlie a spectrum of human congenital eye malformations. Hum Mol Genet 1999; 8: 165-172.

18 Lee $\mathrm{H}$, Sheth V, Bibi M et al: Potential of handheld optical coherence tomography to determine cause of infantile nystagmus in children by using foveal morphology. Ophthalmology 2013; 120: 2714-2724.

19 Gregory-Evans CY, Wang X, Wasan KM, Zhao J, Metcalfe AL, Gregory-Evans K: Postnatal manipulation of Pax6 dosage reverses congenital tissue malformation defects. J Clin Invest 2014; 124: 111-116.

20 Hanson IM, Fletcher JM, Jordan T et al: Mutations at the PAX6 locus are found in heterogeneous anterior segment malformations including Peters' anomaly. Nat Genet 1994; 6: 168-173.

21 Azuma N, Yamaguchi Y, Handa $\mathrm{H}$ et al: Mutations of the PAX6 gene detected in patients with a variety of optic-nerve malformations. Am J Hum Genet 2003; 72: 1565-1570.

22 Valenzuela A, Cline RA: Ocular and nonocular findings in patients with aniridia. Can J Ophthalmol 2004; 39: 632-638.

23 Khaw PT: Aniridia. J Glaucoma 2002; 11: 164-168.

24 Churchill AJ, Hanson IM, Markham AF: Prenatal diagnosis of aniridia. Ophthalmology 2000; 107: 1153-1156. 